\title{
HOW SCIENCE TEACHERS LEARN TO REFLECT BY ANALYZING JOINTLY OBSERVED LESSONS
}

\author{
Dace Namsone \\ The Center for Science and Mathematics Education, University of Latvia, Latvia • \\ dace.namsone@lu.lv \\ Līga Čakāne \\ The Center for Science and Mathematics Education, University of Latvia, Latvia \\ Ilze France \\ The Center for Science and Mathematics Education, University of Latvia, Latvia
}

\begin{abstract}
The aim of the article is to present a teacher's professional learning model implemented within the project PROFILES of FP7 Science in Society. The article reveals the contribution of the joint observation in real-life classroom environment and lesson analyses to the development of the capability of teachers' reflection skills. The survey of teachers, conclusions of experts and teachers' feedback all demonstrate that the model enhances the development of science and mathematics teachers' reflection skills. At the same time the article gives guidelines to follow when this model is practiced with different groups of teachers.
\end{abstract}

\section{Introduction}

The biggest challenge for teachers during the course of implementation of students' scientific inquiry is to acquire teaching methods/techniques which would help develop students' scientific inquiry skills and facilitate their joint work, and through this make real changes happen in the classroom. The implementation of scientific inquiry, which forms the basis of FP7 Science in Society projects of which one is PROFILES, started in Latvia in 2008.

Efficient teaching of inquiry skills in the school is impossible without teachers' understanding of the concept, diversity and continuity of the scientific inquiry, as well as the following skills: ability to identify the learning outcomes of scientific inquiry and their conformity to the expected results; effective use of the teaching and learning strategies for scientific inquiry and effective communication of feedback on students' scientific inquiry.

The initial research carried out in Latvia on teachers' progress of implementation of a scientific inquiry philosophy showed a contradiction between the actual teaching process in the classroom and teachers' opinion of their performance. Analyses into the cause of the contradiction revealed the need to improve teachers' instructional skills as well as their analyses and reflection skills through the implementation of new teachers' learning models. This article will focus on the ways that teachers can benefit from mutual learning to facilitate their reflection skills. 


\section{Theoretical background}

\subsection{Previous studies}

During lesson observation in schools between 2009 and 2011 (observed, transcribed and analyzed 244 lessons of natural sciences subjects and mathematics in 26 schools, grades 79), a group of experts working in the National Center for Education (NCE) under the development project 'Science and Mathematics', witnessed a range of successful teaching performances. Nevertheless, experts concluded that in frequent cases there was a discrepancy between the actual performance of the teachers in the classroom and their understanding of what they were doing which demonstrated during discussions after lessons.

For example, investigating the skills of Latvian chemistry teachers from 2009 to 2011 (Volkinsteine, Namsone, Cakane, 2014), a significant difference was found between the performance of two different teacher groups. Teachers have different levels of effectiveness teaching scientific inquiry - from well-developed performance (group B) to quite limited performance (group A). Group B teachers' practical knowledge comes from workshops, focus group discussions during piloting of curriculum for the upper secondary school as well as the training of analyzing and reflecting on their performance during lessons.

Over a period of three years prior to 2008 group B teachers had been working with the development project 'Science and Mathematics' and learning how to implement scientific inquiry in upper secondary school by leading open lessons; they analyzed and reflected about lessons as well as collaborated with their colleagues to improve their practice. Experience for the three year period was one of the factors influencing results of $\mathrm{B}$ group teachers and their understanding of what they were doing in the lesson, how and why they were achieving goals. This helped group B teachers to have better performance than their colleagues from group A.

The contradiction between the actual situation in the classroom and group A teachers' opinions confirms the idea that in order to develop effective scientific inquiry organization skills, teachers have to have good analysis and reflection skills. In this situation, appropriate professional development models can successfully provide methodological support to effective group A teachers' scientific inquiry organizing skills. These models have to focus on teachers' complete immersion into the lesson and receiving appropriate feedback.

The lack of skills mentioned above has a grounded explanation. Practical theories that guide teachers in teaching are based on practical knowledge (Van Driel, Beijard \& Verloop, 2001). Teachers' practical knowledge is constructed by the teachers in the context of their work integrating experimental knowledge, formal knowledge and personal beliefs (van Driel, Beijard \& Verloop, 2001).

Teachers acquired formal knowledge at the university and in-service training. Traditionally a science subject teacher was educated as a teacher of a single subject 
(chemistry, physics, biology) and acquired a science based program (up to 90\% subjects focused on covering science subject content) in Latvia. Moreover, for a number of years teachers' in-service training was mostly organized as transmission of new information. A school usually employs only one physics, chemistry or biology teacher and the exchange of experience among them or between schools is poor or focuses mainly on delivery of new information. As a result many teachers' beliefs and practical knowledge are limited to their personal practical experience or the manner of how they were taught at school. Teacher is acting in teacher centered manner according to his/her beliefs. Teacher- centered beliefs emphasize the factual and descriptive nature of science as determined by the teacher and transferred to the student (Roehrig\&Luft, 2004).

Upon implementing a different learning philosophy, what happens in practice is the following: the teacher includes the elements of a scientific inquiry philosophy in the traditional information transfer model without understanding that the process of transmitting information is ongoing.

In order to make changes happen, teachers have to be immersed in their own and their colleagues' experience analyzing and reflecting on it. It is crucial to create learning situations that allow teachers to acquire different kinds of experience, take part in discussions, exchange opinions, practice, analyze and reflect on their own and their colleagues' learning, that is, facilitate immersion.

Complete understanding of the implementable approach is not enough to make changes happen in the classroom (for example, inquiry based science education, acquiring new learning methods, practicing them in action and receiving professional feedback). The teacher has to be immersed in his/her performance, develop the necessary analyses skills and improve his/her reflection skills. The importance of the reflection skill is underscored by the fact that it is crucial not only for teaching scientific inquiry but for teachers' daily activity as well as implementing any changes in the future.

\subsection{The PROFILES project philosophy according to teachers CPD}

PROFILES project has triggered substantial discussion regarding promotion of inquirybased science education by enhancing the science teachers' self-efficacy and sense of ownership (Hofstein \& Mamlok-Naaman, 2014). The key goals of the PROFILES CPD approach are to develop teachers professionally, based on the teacher as a learner, as an

effective teacher, as a reflective practitioner who strives to enhance teachers' self-efficacy and ownership and eventually, in some cases, as a leader. Loucks-Horsley, Stiles and Hewson (1996) - quoted from Hofstein \& Mamlok-Naaman (2014) suggested six key principles for creating effective CPD experiences that should be provided for science teachers within PROFILES. These principles are as follows:

1. Provide teachers with opportunities to develop the necessary knowledge and skills and to broaden their teaching approaches, so that they can create better learning opportunities for students. 
2. CPD experiences are driven by a clear, well defined image of effective classroom learning and teaching. Among other factors, they emphasize inquiry-based learning, students' investigations and discovery, and application of knowledge.

3. Use instructional (pedagogical) methods to promote learning for adults to mirror the methods that will be used later by their students.

4. Provide conditions that foster learning in a community of practice (promotion of collegiality and collaboration). Also provide support for other teachers. In addition, CPD is viewed as a lifelong process that is part of school norms and culture.

5. Include assessment. CPD programs must continually be assessed and reviewed regarding engagement, satisfaction, etc.

6. Prepare and support science teachers to serve (at least some of them) in leadership roles if they are inclined to do so. The meaning of leadership in this context is highly aligned with the claim made by Fullan (1991) quoted from Hofstein \& Mamlok-Naaman (2014) regarding: "The ability of a person to bring about changes among teachers and teaching."

The PROFILES project philosophy also emphasizes the role of reflection. PROFILES Professional Reflection-Oriented Focus on Inquiry-based Learning and Education through Science. The letters 'ROF', within the acronym of PROFILES, specifically recognize the concept of the teacher as a reflective practitioner. The Project leaders emphasize that: in particular, it sees reporting back on teacher classroom interventions as an integral part of PROFILES. But 'ROF' covers much more than that. In short, within PROFILES teachers are guided to reflect on whether the module is used in line with the expected approach. The importance of this reflection, as an integral part of the CPD and following on from the classroom intervention by teachers, cannot be underestimated. The opportunity for teachers to share their experiences with other teachers is expected to play a major role in enabling teachers to better appreciate the PROFILES intentions. It is also expected to be a major aspect of moral support in helping teachers to minimize or overcome the multitude of constraints which are likely to arise in embarking on a change of paradigm in their teaching approach and orientation (Bolte, Streller, Holbrook, Rannikmae, Hofstein, Mamlok Naaman, Rauch, 2012).

\subsection{Correlation with sources of literature}

Implementation of scientific inquiry philosophy in the classroom demands from teachers not only new knowledge and skills. It also changes their beliefs what teaching is. It means to act in changing situations. Teacher needs a critical mind and ability to reflect. Reflection can be in action and on action (Niemi \& Jakky-Sihvonen, 2009). Effective CPD needs to provide an opportunity for teachers to reflect on and learn about how new practices can evolve or be modified from existing classroom practice (Harison, Hofstein, Eylon \& Simon, 2006).

If in the Finnish teacher education teachers competence must include the readiness to analyse the situation like a researcher and to make conclusions and decisions to act or to 
change something in a given situation (Niemi \& Jakky-Sihvonen, 2009), then, when developing new teachers' learning models in Latvia, we know that teachers' education has never had such demands and thus most teachers fail to have the respective experience.

It is assumed that improvement in teaching is a collective rather than individual enterprise and that analysis, evaluation and experimentation in concert with colleagues are the conditions under which teachers improve (Rosentholtz, 1991). During the project 'Science and Mathematics,' we came across a successful teacher learning model in a school where a team of science and mathematics teachers included a representative from the school leadership learn together with teachers from other schools. The results obtained corresponded to the views of Fullan (2011): well developed teamwork improves the quality of practices as teachers work and learn from each other. Collaboration within this model was organized as sharing (materials \& teaching strategies) and joint work - where teachers teach, plan or inquire into teaching together. Despite the evidence and the fact that almost every other profession conducts most of its training in real-life settings, very little teacher training takes place in a teacher's own classroom, the precise place in which it would be relevant enough to be most effective (Barber and Mourshed, 2007). We thus focused learning for the teachers on real-life practice at school.

The message is rather about teachers being open to evidence of their impact on students, critiquing each other's impact in light of evidence on such impact, and forming professional judgments about how teachers then need to - and indeed can - influence learning of all students in their class (Hattie, 2012).

There was an obvious necessity to develop a teachers' professional learning model:

- that is based on real-life school practice,

- where teachers learn by collaboration and exchange of experiences,

- where teachers feel their colleagues' support,

- where teachers can learn how to analyze and reflect.

It seems too general, not focused on science education but in practice it is! Implementation of a new philosophy means changing people's believes about different understanding of learning on the whole and about an efficient lesson. Only then can one focus on how to include the particular science teaching methods in the lesson. Stopping at particular teaching methods will leave one on a superficial level which will never change people's believes and practices.

\section{Research methodology}

\subsection{Research question}

The research poses the following question - how does joint lesson observation and analyses facilitate development of teachers' reflection skills? 


\subsection{Data collection and analysis}

In order to determine teachers' understanding of the skills they need to improve, a teacher needs questionnaire (2011, 92 respondents - science and mathematics teachers) served as a tool to study teachers' learning needs for inquiry-based teaching (adapted from PROFILES project).

The questionnaire consisted of 40 questions on teachers' confidence in certain skills and emphasis for professional development. Respondents evaluated each of their skills according to the Likert scale (1- definitely no need to acquire, $5^{-}$a very necessary skill). Six questions covered the teachers' reflection skills - recording the facts and using them as basis for analyses; focus on the efficiency of the lesson; providing and accepting feedback; awareness of own strength and weaknesses; immersion in own professional activity in order to improve teaching.

Teachers provided written feedback after each workshop by giving written answers to the same questions: benefits from lesson observation and from lesson analyses.

The expert participating in the lesson observation and analyses makes a lesson transcription and takes notes of the lesson analyses as well as summarizes teachers' feedback. After seminars, the feedback is coded through content analyses. This helps obtain data on the changes in teachers' understanding of the importance of lesson analyses and depth of reflection.

The impact of the performed cycle of workshops was analyzed with the help of teacher questionnaires after the first and second year of running the model (2012, 74 respondents) and (2013, 82 respondents). Each questionnaire included information about the improvement of teachers' skills in seminars; 6 questions refer to teachers' reflection skills. Evaluation was made according to the Likert scale (o - the skill has not improved, 5completely agree). The reliabilitie (Cronbach's alpha) for each questionnaire is analyzed. $\mathrm{R}$ version 3.1.1 used.

\subsection{Participants involved}

The model was implemented within the NCE innovative experience school collaboration network in cooperation with experts from the Centre for Science and Mathematics Education - 8 people with 5-15 years of experience in teachers' CPD and lesson analyses.

Experts from the Centre for Science and Mathematics Education led workshops, provided feedback and developed the research. Experts and the school team jointly planned the workshop, discussed the plan of lessons to be observed and reviewed the necessary input lessons.

The procedure, specific worksheets for observation and for analysis and the reflection guidelines were created by the experts. Participants had to give feedback after every workshop. During the third phase, the experts' team worked on summarizing the feedback from the teachers and the experts and planned the next workshop.

During the evaluation phase the experts analyzed teachers' feedback. 
Implementation of the model involved teams from 22 schools (urban and rural high schools and intermediate schools from different parts of the country): the total of 82 physics, chemistry, biology and mathematics teachers as well as principals or deputy principals of 22 schools. All participants had a minimum of 3 years collaboration experience developing and implementing the new curriculum. The teams of teachers from the network were divided into 4 regional groups of $5-6$ schools in each group.

For example Riga group included 23 teachers - chemistry, physics, biology and math teachers from 6 schools from the Riga area, plus 6 school leaders.

Learning was carried out during the two school years from November 2011 till April 2013. Each group participated in the two cycles of 5 workshops, each of which took place in a different school and included a real-life observation of lessons with joint lesson analysis, as well as input sessions on a particular issue.

\subsection{How teachers jointly observed lessons}

As noted earlier, studies of the analysis of the current situation, the collaboration experience with teachers in the Project 'Science and Mathematics', piloting of the new curriculum, lesson observations and analysis as well as piloting and accepting the PROFILES project concept of raising teachers' proficiency, lead to a decision to create a model based on the idea of a workshop that represents mutual real-life lesson observation at school and lesson analyses, and build the analyses as a reflection skills training incorporating into the model teacher's multi role principle - learner, teacher, reflective practitioner, leader. Every participant who was leading and open lesson had to take on the role of a leader.

The whole CPD model included three phases: planning and preparation together with the teachers of the school where the workshop is held; workshop at the school with teachers from other schools participating; evaluation.

Development of the reflection skills was based on the idea of a multiple activity cycle performed during joint lesson analyses - as in the action research spiral (Kemis, Taggart, 2000) "Observe - reflect - write - discuss" a few times during every workshop and multiple times during the whole cycle of workshops.

The idea is realized in the main part of the model - the workshop at school. Figure 1 shows the elements of the workshop. The workshop consists of three parts: the introductory part sets the goals and provides the needed input. The second part includes joint observation of lessons (usually, two open lessons for a teacher-learner) and the third usage of certain procedures and experts' supervision in analyzing and reflecting on the teaching and learning practice observed (teacher as reflective practitioner). The second cycle of the workshop introduces an additional session with a particular focus on reflection (analyses of the analyses). 


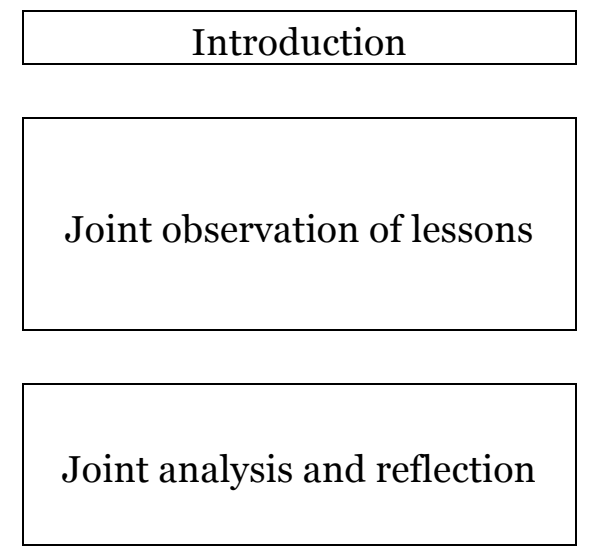

Introduction to focus. Input session

Observing of lesson No 1 (for example, chemistry for chemists)

Observing of lesson No 2 (for example, physics for chemists etc.)

\begin{tabular}{|l|}
\hline Analysis of lesson No 1 \\
\hline Analysis of lessons No 2 \\
\hline Reflection about analysis \\
\hline
\end{tabular}

Feedback from participants

Figure 1 Elements of Workshop at school

The set of topics selected for the workshops, according to the teacher needs, were as follows:

- How to reflect on teaching and learning science. A model of analysis and reflection on the open lesson.

- Teaching scientific inquiry - student-focused teaching. Case studies.

- The development of HOCS (higher order cognitive skills) through scientific inquiry.

- Students' motivation for learning and feedback extended through scientific inquiry.

- Formative assessment in the science classroom.

The above questions were also emphasized during lesson analyses.

Each workshop gave the teachers an opportunity to observe and analyze two lessons one of the subject they were teaching and the other of a different one. The aim was to encourage reflection on transferring different subject teaching practice to teachers' own particular subject as well as immersion into learning from the students' point of view.

Every teacher in the group took the role of a teacher-learner (from others experiences) and a teacher-teacher (with potential of becoming a teacher-leader) to open his/her classroom to colleagues learning. School teams' participants from the school leadership, as well as other interested teachers, practiced how to lead lesson analyses. However the main focus was on the reflection skill - teachers were invited to reflect in writing and orally; they were encouraged to analyze their own performance and their colleagues' lessons; to reflect individually, through discussion with experts and in groups of teachers.

\section{Results and discussion}

As the change of teachers' opinions lies at the core of the progress of teachers' learning, it was important to find out if the teachers were aware of the need to develop their analyses and reflection skills. 
In 2011 teachers of natural sciences (92 respondents) were asked to fill out teacher needs questionnaire (Cronbach's alpha 0.96). Table 1. shows the percentage of teachers replying to the question about their need to acquire a particular skill. (Likert scale).

Table 1 An excerpt from teachers' learning needs self-evaluation summary.

\begin{tabular}{|c|c|c|c|c|c|}
\hline & $\begin{array}{l}\text { definitely } \\
\text { not }\end{array}$ & rather not & $\begin{array}{l}\text { do not } \\
\text { know }\end{array}$ & necessary & $\begin{array}{c}\text { very } \\
\text { necessary }\end{array}$ \\
\hline Observe and fix activities in a collegue's & & & & & \\
\hline $\begin{array}{l}\text { lesson; notice the positive and compose a } \\
\text { follow up question }\end{array}$ & $10.9 \%$ & $34.8 \%$ & $33.7 \%$ & $19.6 \%$ & $1.1 \%$ \\
\hline $\begin{array}{l}\text { Analyze the lesson from the viewpoint of } \\
\text { the student and teacher's performance } \\
\text { efficiency }\end{array}$ & $5.4 \%$ & $35.9 \%$ & $30.4 \%$ & $25.0 \%$ & $3.3 \%$ \\
\hline Provide useful feedback to colleagues & $6.5 \%$ & $33.7 \%$ & $32.6 \%$ & $26.1 \%$ & $1.1 \%$ \\
\hline $\begin{array}{l}\text { Accept collegues' feedback and } \\
\text { recommendations }\end{array}$ & $5.4 \%$ & $39.1 \%$ & $35.9 \%$ & $18.5 \%$ & $1.1 \%$ \\
\hline Evaluate personal strong and weak sides & $13.0 \%$ & $27.2 \%$ & $34.8 \%$ & $22.8 \%$ & $2.2 \%$ \\
\hline $\begin{array}{l}\text { Analyse personal performance in order to } \\
\text { be able to improve }\end{array}$ & $12.0 \%$ & $23.9 \%$ & $30.4 \%$ & $29.3 \%$ & $4.3 \%$ \\
\hline
\end{tabular}

Data interpretation showed that teachers fail to see the need to develop their analyses and reflection skills - the need to acquire these skills was ranked the lowest (compared to the skills listed). At the same time the aforementioned skills have the highest "do not know" percentage, which might mean that teachers lack an opinion regarding the necessity of these skills and that teachers do not see them as part of their professional competences.

The questionnaire as well as teachers' feedback analyses after the first workshops proves the existence of the need to improve teachers' reflection skills and points to the deep contradiction between teachers' performance in the classroom and their own understanding about it.

According to the experts' conclusion, teachers possess insufficient reflection skills. For example, the most common teachers' feedback after first observed lessons was the following: "It is always interesting to observe a colleague's lesson"; "I liked the game"; "An excellent lesson"; "Now I am going to use these work sheets in my lesson". Teacher E, who was leading the lesson: "Tell me how to do it, and I will do it!"

During the workshops these skills were developed simultaneously with other skills or they are acquired as indirect gain. The participants focus on lesson observation (at least during the initial stage), and the related analysis process is built as a reflection skills training.

Teachers were actively involved in the development and attendance of practical workshops giving added value to their skills. Teachers of the national network agree that they benefited most from observation of practical teaching and learning methods in their colleagues' lessons. According to the teachers' questionnaire (2012, Likert scale $0-5$, 
Cronbach's alpha 0.87), teachers indicate that leading and analyzing lessons has helped them to become a more competent professional (see Table 2).

Table 2 Teachers' benefits from participation in lesson observation and analyses in workshops refer to reflection skills (number of teachers who gave the respective answer \%).

\begin{tabular}{|c|c|c|}
\hline Leading lessons in seminars and analyses of my lessons & $\begin{array}{c}\text { Completely } \\
\text { agree }\end{array}$ & Agree \\
\hline $\begin{array}{l}\text { Provided an opportunity for professional evaluation of } \\
\text { strengths and weakness in my practice }\end{array}$ & $62 \%$ & $30 \%$ \\
\hline I've improved the ability to reflect on my work with colleagues & $58 \%$ & $39 \%$ \\
\hline I've learnt to listen to my colleagues' suggestions & $57 \%$ & $37 \%$ \\
\hline $\begin{array}{l}\text { Observation of and participation in analyses of colleagues' } \\
\text { lessons }\end{array}$ & $\begin{array}{c}\text { Completely } \\
\text { agree }\end{array}$ & Agree \\
\hline Improved my skill of seeing facts and basing analysis on them & $57 \%$ & $41 \%$ \\
\hline $\begin{array}{l}\text { I've learned together with colleagues to reflect on the meaning } \\
\text { and effectiveness of the lesson }\end{array}$ & $55 \%$ & $42 \%$ \\
\hline
\end{tabular}

Some examples from teachers' feedback:

I have acquired a skill to critically evaluate and analyze my own and my colleagues' lessons; to see the positive and to use it.

I was learning to see the difference between what I have true knowledge and skills of and what I think I have knowledge of.

Nervousness before the open lesson - it is normal and it helps to focus on the goal. Lesson analysis gives a different perspective of the situation - my colleagues often see more of the positive than I do myself. It is very inspiring.

However, not all teachers are able to reflect. For example, teacher X said: I am still in the process of finding out what my weak points are. I cannot understand it from the questions asked. (During analysis colleagues ask questions about the disputable issues to the lesson leader.)

Teachers identified opportunities and expressed recommendations on the lesson analyses process: Maybe a new form allowing more precise evaluation of the lesson has to be sought? Maybe each observer should focus on just one particular thing and then everybody takes turns to reflect on it?

According to the teachers' questionnaire (2013, Likert scale 0-5, Cronbach's alpha 0.94) teachers in collaboration with colleagues during the workshops improved their lesson observation and analyses skills (69\% - fully agree), accepted their colleagues' feedback (46\%), provided feedback and recommendations (28\%); understood the need to be immersed in their professional activity (77\%).

From experts' notes:

During lesson observation teachers take very detailed notes to be able to give arguments during discussion. 
Irrespective of the 'heat', people appreciate that discussions and opinions and ideas exchange are the only way to improvement. I really enjoyed and highly valued the fact that we could openly discuss an issue and have different opinions.

The research concludes that the development of teachers' reflection skills occurs. The conclusion is supported by the responses of teachers, the conclusion of experts in focus groups and teachers' feedback. Moreover, on completion of the cycle of the workshop experience the time and depth of teachers' reflection is increased and teachers' awareness of the importance of lesson analyses is deepened. At the beginning of the cycle teachers would ask: What is the sense of getting so detailed? The questions were in large the same in the middle stage: It is all the same over and over again, it is getting boring and Aren't we focusing on the same things too much? However at the end of the second cycle the nature of the questions had completely changed: We ran out of time! We had no time to discuss everything we wanted!

Experts' analyses of the teachers' feedback single out three levels showing the contribution of the training to a gradual development of teachers' analyzing and reflection skills. The easiest level is to take particular elements from the observed lesson and use them 1:1 in a similar situation in the classroom. On the second level the teachers advance to seeking answers to the following questions: what is happening, how and why it is happening in this lesson and how I can incorporate it into my practice. On the third level the teachers perform independently and analyze the effect of the implemented changes on the performance.

It is important to note that the research project includes experienced and enthusiastic teachers eager to make changes happen and that the teachers and experts enjoy mutual trust, which certainly contributes to the excellent outcome. Experts' proficiency grows together with the participants' experience jointly working on the development of a new model of teacher professional learning. This means that a new expert implementing the model 1:1 among inexperienced teachers may encounter certain difficulty. Experts' experience through workshop cycles in other groups of teachers allows us to conclude that in order to benefit from reflection over a lesson, a new team of teachers with insufficient reflection skills needs a preliminary training period.

Before lesson observation in a real class environment teachers acquire precise lesson transcript skills which helps them recognize particular facts and use them during analysis, see particular steps in the lesson and explain the idea of each step to the students, compose questions for discussion with the teacher, analyze video lessons and write lesson plans. According to our experience, at the beginning the teachers fail to engage in detailed analyses; they are very critical speaking about what should be improved and how they would have performed if they had been leading the lesson. Teachers tend to maintain their traditional role of a teacher - identify mistakes, find 'correct' ways, etc. Questions asked to a colleague are usually 'loaded' - they contain evaluation and often even fail to have a form of a question; they sound like a statement or opinion. In such situations the expert's 
knowledge of professional analysis management and maintaining its focus on the topic in subject is crucial.

At the beginning the teachers are mostly superficial observers. Their main focus is on the activity of the teacher. What is going on with students in the classroom - how they learn, how they express their opinions, what exactly they say during discussions, etc. at this phase is of lesser importance. This can be explained with the traditionally dominating role of the teacher in the lesson and teachers' lack of immersion experience in students' learning activity.

There are teachers who are very unwilling to take notes during observation, and later during analysis they are not able to name particular facts; sometimes instead of what can be heard and seen lesson transcripts show interpretations and conclusions. Teachers lack skills of teaching process analyses and reflection; so far they have had no need for detailed analyses or for seeking deeper meaning of the activity; they lack argumentation skills.

Analyses of the mutually observed lessons have to be objective, open, at the same time focusing on the positive and possibilities to change. Building a relationship of trust is a time consuming effort.

In order for the participants to enjoy maximum benefit and satisfaction the lesson they are observing has to be sensible, efficient (clearly targeted towards the student's learning goal, starting exactly at the point where the student is in the learning process, providing feedback); it has to ensure positive lesson experience to the observers. This encourages a positive environment for discussion of different possibilities, model benefits of other strategies etc. In order to have a good lesson it is crucial to have good teacher-expert collaboration and discussion during the seminar preparation phase, when through lesson plan analyses the unused opportunities are sought and alternatives discussed. This kind of collaboration ensures the proper emphasis on the topic of the seminar. There are school teams where teachers provide each other with professional support, jointly plan lessons and analyze their colleagues' lesson plans daily rather than just for the purpose of seminars.

The key to the success of the model of a real-life observation of lessons with joint lesson analysis is mutual trust (among the colleagues, counterparts from other network schools, and the relationship of trust among the teachers and experts), enthusiastic teachers who are willing to immerse themselves in the practice, professional experts; development, collaboration and creation of the social capital oriented school leadership.

A combination of several CPD models ensures even better results to develop reflection skills. Teachers who are part of collaboration groups for action research show high reflection skills and their performance analyses skills.

It is crucial for teachers to form a habit of personal reflection on their professional activity, to seek solutions, follow the changes and evaluate them. The teachers involved emphasize the significance of collective reflection in like-minded groups during action research as well as jointly analyzing lessons. The above expands the area of individual 
experience, helps to provide feedback and creates an environment favorable for teachers' learning.

\section{References}

Barber, M. \& Mourshed, M. (2007). How the world's best performing school systems come out on top. McKinsey \& Co.

Bolte, C., Streller, S., Holbrook, J., Rannikmae, M., Hofstein, A., Mamlok Naaman, R., Rauch, F. (2012). Introduction into the PROFILES Project and its Philosophy. In C. Bolte, J. Holbrook, F. Rauch (Eds.), Inquiry-based Science Education in Europe: Reflections from the PROFILES Project (pp. 31-42). Berlin: Freie Universität Berlin.

Fullan, M. (2011). Whole System Reform for Innovative Teaching and Learning.In Innovative teaching and learning research. 2011 Findings and Implications. On http://www.itlresearch.com/images/stories/reports/ITL\%20Research\%202011\%20Findings\%20 and\%20Implications\%20-\%20Final.pdf

Harrison, C., Hofstein, A., Eylon, B., \& Simon, S. (2006). Evidence based professional development of science teachers in two countries. International Journal of Science Education, 30(5), 571-591.

Hattie, J. (2012). Visible learning for teachers. Maximizing impact of learning. London and New York: Routledge.

Hofstein, A., Mamlok-Naaman, R. (2014). Case Studies on PROFILES Teacher Training (CPD) and Ownership. In C. Bolte, J. Holbrook, R. Mamlok-Naaman, F. Rauch (Eds.). Science Teachers' Continuous Professional Development in Europe. Case Studies from the PROFILES Project (pp. 161-164). Berlin: Freie Universität Berlin.

Kemmis, S., \& McTaggart, R. (2000). Participatory action research. In N. Denzin and Y. Lincoln (Eds.), Handbook of Qualitative Research. London: SAGE.

Niemi, H., \& Jakky-Sihvonen, R. (2009). Teacher education curriculum of secondary school teachers. Revista de educacion, 350, 173-202.

PROFILES Project http://www.profiles-project.eu/

Roehrig, G.H., \& Luft, J.A. (2004). Constraints experienced by beginning secondary science teachers in implementing scientific inquiry lessons. International Journal of Science Education, 26(1), 3-24.

Rosentholtz, S.I. (1991), Teachers workplace: The social organization of schools. Harlow, UK: Longman group.

Van Driel, J., Beijaard, D.,\& Verloop, N. (2001). Professional development and reform in science education: The role of teachers' practical knowledge. Journal of Research in Science teaching, $38(2), 137-158$.

Volkinsteine, J., Namsone, D., Cakane, L. (2014). Latvian chemistry teachers' skills to organize student scientific inquiry. Problems of education in the 21st Century, 59, 86-98. 
NAMSOME ET AL. 